ARTIGO

\title{
IDENTIFICAÇÃO DE RESINAS PLÁSTICAS EM EMBALAGENS PRESENTES NO COMÉRCIO VAREJISTA DE ALIMENTOS
}

\section{IDENTIFICATION OF PLASTIC RESINS IN PACKAGING PRESENT IN THE FOOD RETAIL TRADE}

\author{
Juliana Moura de Sampaio Arruda' \\ Centro Universitário São Camilo - São Paulo, São Paulo. Brasil. \\ https://orcid.org/0000-0001-9152-9601 \\ julianaarruda.nutricionista@gmail.com \\ Vanessa Bernardo Uehara² \\ Centro Universitário São Camilo - São Paulo, São Paulo. Brasil. \\ https://orcid.org/0000-0003-4177-4371 \\ vvam@bol.com.br
}

${ }^{1}$ Administração do Projeto, Escrita - Primeira Redação, ${ }^{2}$ Administracao do Projeto, Análise Formal, Escrita - Revisão e Edição

\section{RESUMO}

O crescimento do mercado de embalagens e, concomitantemente, dos resíduos sólidos e descarte de embalagens de alimentos reforça a importância do símbolo de identificação do material no rótulo. O presente estudo teve como objetivo identificar as embalagens de alimentos encontradas no varejo com simbologia de identificação da resina e os principais materiais utilizados em suas embalagens. Foram avaliadas 283 embalagens de produtos das categorias chocolate, biscoito, frutas e legumes. A ausência da resina de identificação do material foi observada em $67 \%$ dos produtos. O principal material encontrado, no Grupo Inspeção Rótulo (GIR), foi o PP - utilizado em 55 das 94 embalagens. Os resíduos de embalagens de alimentos e de plástico são um problema ambiental tangível. No entanto, para observar melhoras é importante compartilhar a responsabilidade e unir esforços. Contudo, no âmbito da indústria de alimentos ainda é observado no mercado brasileiro uma deficiência na identificação dos diferentes materiais.

Palavras-chave: Embalagem de Alimentos. Polímeros. Reciclagem.

\begin{abstract}
The growth of the packaging market and, at the same time, of solid waste and food packaging disposal reinforces the importance of the material identification symbol on the label. This study aimed to identify food packaging found in retail with resin identification symbology and the main materials used in their packaging. A total of 283 packages of products in the chocolate, biscuit, fruit and vegetable categories were evaluated. The absence of material identification resin was observed in $67 \%$ of the products. The main material found in the GIR group (Inspection Label Group) was PP - used in 55 of the 94 packages. Food packaging and plastic waste is a tangible environmental problem. However, to see improvements it is important to share responsibility and join efforts. However, within the food industry, a deficiency in the
\end{abstract}


identification of different materials is still observed in the Brazilian market.

Keywords: Food Packaging. Polymers. Recycling.

\section{INTRODUÇÃO}

O mercado de embalagens no Brasil vem crescendo de forma significativa nos últimos anos. Segundo a Associação Brasileira de Embalagens (ABRE), o país movimentou mais de 92,9 bilhões de dólares - com aumento de 22,3\% em relação ao ano anterior - ocupando a quarta posição entre os países que mais consomem embalagens atrás apenas do Japão, EUA e China (DATAMARK, 2019). O segmento de embalagem para alimentos por sua vez, no ano de 2020, apresentou um crescimento de $2,5 \%$ em relação ao ano anterior (ABRE, 2020).

Existe uma ampla variedade de materiais e formas que podem compor as embalagens, porém, de acordo com Datamark, no ano de 2016, os principais materiais utilizados no mercado alimentício foram: plástico, vidro, metal, embalagens flexíveis e papel. Além disso, vale enfatizar que no mesmo ano o mercado alimentício foi responsável por $68,4 \%$ do consumo total de embalagens. De forma complementar, no ano de 2020 , segundo a ABRE (2020), o plástico teve a maior participação de produção total de embalagens (39,6\%) seguido das embalagens de papel/ papelão com 31,6\%, metálicas com $19,9 \%$ e vidro com $4,5 \%$.

O plástico é um dos principais materiais utilizados pela indústria de alimentos devido a suas propriedades, baixo custo, leveza e flexibilidade. Em sua maioria, porém, é produzido de fontes não renováveis como o petróleo e emite, durante o processo, gases poluentes. Esse cenário ainda é agravado com o descarte desordenado que contribui ainda mais com o impacto ao meio ambiente (LADIM et al., 2016).

No ano de 2019, segundo a World Wildlife Fund (WWF, 2019), o Brasil foi o $4^{\circ}$ maior produtor de lixo plástico no mundo, 11,3 milhões de toneladas - atrás apenas dos EUA, China e Índia. Estima-se dessa forma que, em média, é produzido um quilo de lixo plástico por habitante a cada semana - o equivalente à produção de 212 mil toneladas de resíduos plásticos no Brasil (BÖLL, 2020). Esse fato ainda é agravado considerando o destino desses materiais, apenas $1,2 \%$ desse material é reciclado enquanto 1 milhão de toneladas não são recolhidas e 7,7 milhões de toneladas acabam em aterro sanitário.

Cabe ressaltar ainda que cerca de dois terços de todo resíduo sólido do país, o equivalente a 99.333 toneladas, correspondem à embalagem de alimentos. Outro fator relevante a ser observado é que cerca de $80 \%$ das embalagens descartadas nos resíduos domésticos são 
de uso único (IDEC, 2005; MEC, 2005). Assim, apesar da embalagem apresentar uma importância social e econômica, é inquestionável a dualidade de suas características efêmeras e presença de materiais duráveis.

Durante 0 processo de desenvolvimento de um produto alimentício, a embalagem não deve ser considerada como parte isolada na cadeia, mas sim integrada ao sistema de valor do produto. Dessa forma, é importante considerar todas suas interações ao longo do ciclo de vida considerando também, além da interação como o produto, a forma de consumo e descarte pelo consumidor (NEGRÃO; CAMARGO, 2008; BARBOSA, 2014).

Considerando a alta rotatividade das embalagens e com a finalidade de apoiar a reciclagem, foram criadas normativas que harmonizam a identificação da respectiva matéria-prima. Tais normas estabelecem a obrigatoriedade de símbolos de identificação do material em sua constituição - as embalagens plásticas seguem a NBR 13230 enquanto aos demais matérias é aplicada a NBR 16182. Quando aplicada de forma correta, portanto, a simbologia contribui com o descarte seletivo e, concomitantemente, com a melhora da cadeia de reciclagem no setor de embalagens.
Mesmo com o crescimento da produção cientifica no cenário mundial que destaque a importância da sustentabilidade no âmbito das embalagens de alimentos ainda é escasso o número de artigos científicos que abordem as embalagens de alimentos no mercado brasileiro. Não obstante, Coltro (2013) evidenciou que somente $50 \%$ das embalagens plásticas flexíveis apresentavam símbolo de identificação de resinas.

Dessa forma, verifica-se a importância de avaliar a presença dos símbolos de identificação das resinas de embalagens de alimentos - considerando que a presença da simbologia pode propiciar e impulsionar a reciclagem da embalagem pós-consumo. Assim, o objetivo do presente estudo é avaliar as embalagens de alimentos encontradas no varejo, com simbologia de identificação da resina e os principais materiais utilizados em sua composição atualmente pelo setor.

\section{MATERIAL E MÉTODOS}

A coleta de dados foi realizada entre setembro e outubro de 2020 , em dois supermercados de médio porte em bairros nobres da cidade de São Paulo - SP.

Foram avaliadas 283 embalagens de alimentos, classificados em: produtos importados, nacionais e orgânicos nas 
categorias: Chocolate, Biscoitos, Frutas e Legumes.

Os critérios de inclusão dos produtos foram: Frutas e Legumes sem processamento prévio e embalados no fornecedor, chocolate em formato de barra e biscoitos doce e salgados (de $80 \mathrm{~g}$ a $420 \mathrm{~g}$ e de $100 \mathrm{~g}$ a $320 \mathrm{~g}$, respectivamente). A simbologia de identificação do material da embalagem foi observada com base nas instruções normativas NBR 13230, para embalagens plásticas e NBR 16182 para os demais materiais.

Os produtos foram divididos em: Grupo GIR (Grupo inspeção rótulo) - que apresentavam no rótulo a simbologia de identificação da resina e Grupo GIV (Grupo inspeção visual) - que não apresentavam no rótulo a simbologia de identificação do material. Neste caso, foi levado em consideração o material aparente, realizando-se uma análise visual, após pesquisa e classificação detalhada dos tipos de materiais e composição existentes no mercado de embalagens de alimentos. Foram observados os seguintes critérios: composição de embalagens e presença de embalagem primária ou secundária.

As embalagens foram analisadas em todas as faces.

\section{RESULTADOS E DISCUSSÃO}

O polipropileno (PP) é a principal resina plástica consumida no mundo. Sua versatilidade possibilita aplicação em diversos setores, no entanto, a principal consumidora é a indústria de embalagens - representando cerca de $26 \%$ da produção mundial de plástico (WEC, 2016).

No setor de embalagens de alimentos, essa resina tem ampla utilização, principalmente em produtos desidratados e gordurosos por atuar como uma boa barreira a gases e vapor. Além disso, por proporcionar uma boa aparência e alto brilho, é amplamente utilizada no acondicionamento de bolachas $(\mathrm{HIRSCH}$, 1991).

Conforme evidenciado na Tabela 1, o PP foi a principal resina encontrada nas embalagens do grupo GIR. Além disso, cabe destacar que sua utilização foi observada apenas no grupo dos chocolates (29 itens) e bolachas (21 itens).

No ano de 2020, segundo a Associação Brasileira da Indústria do Plástico (ABISPLAST, 2020), esse polímero teve a maior participação no consumo de resinas no Brasil (37\%). A ampla utilização de PP nas embalagens de alimentos tem motivado a busca por materiais mais sustentáveis, considerando que, apesar de suas características de baixo custo e versatilidade, são produzidos a partir do petróleo e não são biodegradáveis - estima-se que tal material demora de 250 a 400 anos para se decompor no meio ambiente (BÖLL, 2020). 
Tabela 1 - Resinas de identificação do grupo GIR por categorias disponíveis nos estabelecimentos de São Paulo, 2020.

\begin{tabular}{cccccc}
\hline GIR & Frutas & Legumes & Chocolate & Biscoito & Total \\
\hline PP & 0 & 0 & 22 & 29 & 51 \\
PET & 0 & 0 & 0 & 3 & 3 \\
Outro "7" & 0 & 0 & 0 & 11 & 11 \\
Papel & 0 & 0 & 1 & 9 & 10 \\
Celulose & 0 & 0 & 3 & 3 & 6 \\
Papel Cartonado & 0 & 0 & 0 & 1 & 1 \\
Compostável & 0 & 0 & 2 & 0 & 2 \\
Oxibiodegradável & 2 & 1 & 0 & 0 & 3 \\
PP & 0 & 5 & 0 & 0 & 5 \\
Biodegradável & & & & & \\
*GIR - Grupo inspeção rótulo. & & & &
\end{tabular}

$\mathrm{Na}$ categoria de frutas e legumes, apenas oito itens apresentaram no rótulo a simbologia de identificação da resina.

\subsection{Avaliação da resina técnica de} identificação do material

A identificação do material no rótulo da embalagem, bem como orientações de descarte e reutilização podem atuar de forma a disseminar o consumo consciente, e orientar o consumidor quanto ao destino adequado pós-consumo. A identificação técnica da simbologia da resina presente nas embalagens, por exemplo, facilita a etapa de triagem dos diversos resíduos, sendo fundamental nas recicladoras e podendo, também, favorecer a logística reversa (ABRE, 2016). Conforme evidenciado na Tabela 2, entretanto, 189 itens avaliados não apresentavam a descrição do material no rótulo. Destes, destacam- se as frutas e legumes com os números mais altos (44 e 77 produtos, respectivamente) sem a simbologia de identificação no rótulo.

Tabela 2 - Local de descrição do material, nos grupos GIR e GIV, para frutas, legumes, chocolate e bolacha disponíveis nos estabelecimentos de São Paulo, 2020

\begin{tabular}{cccccc}
\hline Grupo & Frutas & Legumes & Chocolate & Biscoito & Total \\
GIR & 44 & 77 & 37 & 31 & 189 \\
GIV & 2 & 6 & 31 & 55 & 94 \\
\hline
\end{tabular}

*GIR - Grupo inspeção rótulo; GIV - Grupo inspeção visual.

A identificação não garante que o material seja reciclado ou que seja adequado para reciclagem. Apesar disso, todas as embalagens devem conter a identificação correta dos materiais para minimamente não comprometer a qualidade da cadeia de reciclagem. Nesse sentido ainda vale destacar que, segundo a ABIPLAST (2019), a aplicação efetiva das normas de padronização de identificação é uma oportunidade para aumentar a reciclagem.

Mesmo após a implementação das normativas NBR 13230 (ABNT, 2008) e NBR 16182 (ABNT, 2013), somente 33\% 
das embalagens apresentavam a simbologia técnica de identificação no rotulo. De forma complementar, Coltro et al. (2013) e Coltro et al. (2009), ao avaliarem embalagens alimentícias no mercado brasileiro, observaram que 59\% das embalagens plásticas flexíveis e $83 \%$ das embalagens plásticas rígidas apresentavam a identificação da resina no produto.

Cabe ainda salientar que as instruções normativas pouco evoluíram durante esses últimos anos. Por se tratar de um mercado que vem crescendo de forma significativa e incluindo novas tecnologias, a falta de atualização desse sistema pode culminar na não identificação no produto. Nesse sentido, destaca-se um desequilíbrio entre a inércia dos padrões determinados em consenso em relação à diversidade de materiais utilizados pelo setor de embalagens de alimentos. $\mathrm{Na}$ China, por exemplo, o sistema evoluiu de forma a classificar 140 códigos de identificação de plástico (ISO, 2008).

Também foi observado no presente estudo que, nas categorias com maiores quantidades de produtos sem identificação, as frutas e legumes, mesmo quando presente a simbologia na embalagem, a identificação da mesma poderia ser aprimorada, considerando que os frascos e embalagens de acondicionamento dos produtos geralmente apresentavam invólucros externos e adesivos que não possuíam discriminação no rótulo.

Em contraste, conforme evidenciado no gráfico 1 , as bolachas e chocolates apresentaram identificação do material em $59 \%$ e $33 \%$ produtos, respectivamente. Além disso, vale destacar que no rótulo, o material do envoltório e do berço/bandeja eram informados de forma distinta por grande parte dos itens correspondente à categoria das bolachas. Tais informações, quando descritas de forma a diferenciar a composição dos materiais, pode atuar como recurso para o consumidor destinar 0 material de forma correta para a reciclagem.

Gráfico 1 - Porcentagem total de produtos, por categoria, no grupo GIR e GIV, dos produtos alimentícios disponíveis nos estabelecimentos de São Paulo, 2020.

\section{Descrição do material}

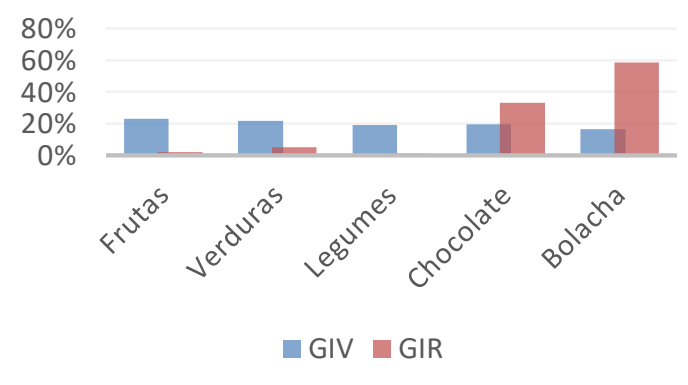

*GIR - Grupo inspeção rótulo; GIV - Grupo inspeção visual.

Embora a resina de identificação não tenha como objetivo esclarecer ao consumidor o tipo de material utilizado, no entanto, a forma que este percebe e compreende a simbologia pode facilitar a 
separação dos resíduos e encorajá-lo a fazer uma classificação adequada (NETMAT et al., 2019). Tendo como exemplo, $48 \%$ da população australiana (BOOMERANG ALLIANCE, 2005) e 61\% dos britânicos (SOE, 2020) não compreendem a simbologia básica de identificação dos materiais. O desconhecimento do consumidor pode prejudicar a confiança na reciclagem, além de levar a níveis mais elevados de contaminação do fluxo de reciclagem e, consequentemente, impactar na viabilidade econômica do sistema de reciclagem.

Diversos fatores afetam 0 comportamento e decisão do consumidor frente à reciclagem da embalagem pós consumo, como por exemplo a facilidade de higienizar a embalagem, distância entre a estação de reciclagem, percepção e/ou conhecimento do valor de reciclagem do material, além de atributos visuais como símbolos atraentes (KLAIMAN et al., 2017; LANGLEY et al., 2011).

Dessa forma, fica evidente que tanto a embalagem quanto a identificação do material no rótulo, atuam como um elo entre o fabricante da embalagem e a indústria de reciclagem. Assim, a responsabilidade da identificação e educação de descarte deve ser compartilhada entre todos do sistema. $\mathrm{Na}$ Suécia por exemplo, em 1994 foi introduzida a "Lei de responsabilidade do produtor" para que as empresas que produzem, importam ou vendem embalagens sejam responsáveis por orientar o consumidor quanto ao descarte da embalagem e os municípios por fornecer informações a respeito da classificação dos resíduos nas diferentes lixeiras. Além disso, o país conta com 5.000 estações de reciclagem, que são financiadas por 'taxas de embalagens' pagas pelas empresas de embalagens, e possuem um sistema de identificação dos diferentes materiais de forma automática em unidades de triagem (FTI, 2019; SDW, 2018).

\subsection{Utilização de materiais sustentáveis}

No Brasil e no mundo é notório a crescente preocupação do consumidor com o impacto de suas escolhas no meio ambiente resultando em um consumo mais sustentável. Nesse sentido, segundo relatório elaborado pelo Instituto de Pesquisa (IPSOS, 2019), dois terços dos brasileiros acreditam que as empresas de alimentos e bebidas deveriam usar apenas embalagens sustentáveis. Apesar disso, conforme evidenciado na Tabela 3, apenas 10 produtos apresentavam embalagens sustentáveis - com utilização de material compostável, oxibiodegradavel e "PP Biodegrável".

Os bioplásticos são considerados como potenciais soluções para o acúmulo de lixo plástico no meio ambiente. Várias 
(1)

de plásticos foram

benefícios são evidenciados apenas em desenvolvidas com o objetivo de deteriorar mais rapidamente e diminuir o impacto ambiental. No entanto, embora existam normativas europeias (SWD, 2018) e americanas (NYSB, 2019), que sustentem metodologias para avaliar o efeito dos novos polímeros no meio ambiente, os condições industriais. Além disso, independente da origem do polímero, a embalagem só terá uma decomposição adequada se houver um fluxo e volume de resíduos compostáveis apropriados para os padrões do compostor industrial (MARKOWICZ; SZYMANSKA, 2019).

Tabela 3 - Materiais sustentáveis utilizados nas embalagens, por categoria, conforme descrição do material de forma visual e encontrada no rótulo do Grupo GIR, dos produtos alimentícios disponíveis nos estabelecimentos de São Paulo, 2020.

\begin{tabular}{ccccc}
\hline Material & Frutas & Legumes & Chocolate & Biscoito \\
\hline Compostável & 0 & 0 & 2 & 0 \\
Oxibiodegradável & 2 & 1 & 0 & 0 \\
PP & 0 & 5 & 0 & 0 \\
Biodegradável & & & & \\
${ }^{*}$ GIR - Grupo inspeção rótulo. & & &
\end{tabular}

Para obter o máximo benefício dos bioplásticos, é essencial ter definições claras na rotulagem que indique a forma adequada de uso e descarte da embalagem. No presente estudo, os cinco produtos da categoria dos legumes apresentavam na embalagem a descrição e simbologia de "PP Biodegrável", mas não apresentavam no rótulo recomendações de descarte pós consumo. O mesmo aconteceu com os produtos que utilizavam o material oxibiodegradavel da categoria de frutas (2 itens) e legumes (1 item). A ausência de informações claras ao consumidor somada ao destaque das propriedades "compostáveis" pode tornar o consumidor mais propenso a jogar no lixo ao invés de reciclá-la.
Embora os polímeros bioplásticos apresentem um potencial de redução do risco ambiental, é necessário conscientizar o consumidor e fornecer orientações completas sobre o descarte. Reforçando essa perspectiva, Song et al. (2009), evidenciaram os plásticos biodegradáveis, por apresentarem em sua composição adição de amido, fibras ou outros compostos naturais, que podem comprometer os processos atuais de reciclagem. Além disso, nos aterros e em condições anaeróbias, tais polímeros podem provocar aumento da produção de metano.

De forma complementar, Napper e Thompson (2019), ao avaliarem a decomposição do plástico convencional, compostável, biodegradável e 
oxibiodegradaveis em diferentes ambientes (ao ar livre, submersos na água do mar, enterrado no solo e no laboratório) observaram que todos os materiais após nove meses ao ar livre se fragmentaram em microplásticos. Além disso, após três anos todos os materiais ainda estavam presentes no meio ambiente, reforçando que ainda não é claro o nível de deterioração em comparação com o plástico convencional.

As evidências até o momento são inconclusivas a respeito do real efeito dos polimentos bioplásticos no meio ambiente. A falta de padronização dos componentes permitidos causa a adição de diferentes recursos no material. Assim, além de adicionar compostos que favorecem a biodegradação, já foi observada a presença de metais pesados como chumbo, cobalto, níquel, cromo, ferro, entre outros nas amostras de embalagens (MARKOWICZ; SZYMANSKA, 2019).

Muitos países têm se mobilizado para tomar medidas legais frente às novas evidências científicas do bioplástico. Na União Europeia (EU) por exemplo, diversos relatórios transitam no parlamento com estratégias de políticas públicas para lidar com os resíduos plásticos e de embalagens de alimentos. Nesse sentido, a diretiva 2019/904 (EU, 2019) que visa reduzir o impacto dos produtos plásticos de uso único - incluindo recipientes de frutas e vegetais - propõe iniciativas de redução do consumo, sensibilização do consumidor bem como metas de coletas até 2025 e 2029.

A proposta entra em vigor na União Europeia em 2021 banindo a utilização de plásticos oxidegradáveis e plásticos que apresentam materiais alternativos. Quando não houver substituto no mercado, o produtor deve assegurar que todo produto de uso único informe, de forma legível e visível, ao consumidor meios de descarte do resíduo e o impacto negativo da eliminação inadequada (EU, 2019).

Já as medidas de redução da utilização de plástico de uso único no Brasil, não são observadas de forma harmônica e padronizada por todo o país. A proibição de canudos plásticos foi estabelecida no estado do Rio de Janeiro, Fortaleza, Salvador, Santos e de São Paulo - este por sua vez, ampliou a abrangência da legislação para copos, talheres e pratos plásticos descartáveis (BRASIL, 2019).

\section{CONCLUSÃO}

A disposição inadequada da identificação no rótulo pode impactar no descarte de embalagens de forma inapropriada e acentuar o problema ambiental já existente em decorrência da grande utilização de plásticos. Ampliando o foco para produtores de alimentos, $67 \%$ dos produtos avaliados não apresentavam 
a resina de identificação do material no rótulo ou embalagem. Além disso, o principal material identificado no rótulo (GIR) foi o PP reforçando que, embora novas tecnologias e polímeros já estejam disponíveis no setor de embalagens, o polipropileno ainda é muito utilizado no mercado alimentício brasileiro.

\section{REFERÊNCIAS BIBLIOGRÁFICAS}

ASSOCIAÇÃO BRASILEIRA DE NORMAS TÉCNICAS. NBR 13230: Embalagens e acondicionamento plásticos recicláveis Identificação e simbologa. Rio de Janeiro, 2008.

ASSOCIAÇÃO BRASILEIRA DE NORMAS TÉCNICAS. NBR 16182: Embalagem e acondicionamento - simbologia de orientação de descarte seletivo e de identificação de material. Rio de Janeiro, 2013.

ABRE. Dados do Setor: ano de 2020. Disponível em:

https://www.abre.org.br/dados-dosetor/2020-2/. Acesso em: 22 de julho de 2021.

ABRE. Embalagem e sustentabilidade: desafios e orientações no contexto da economia circular. Disponível em: https://www.cetesb.sp.gov.br/wpcontent/uploads/sites/11/2016/04/embalag em_sustentabilidade.pdf. Acesso em 20 de novembro de 2020.

APIBLAST. Preview 2020. Mai, 2021 Disponível em: http://www.abiplast.org.br/publicacoes/pre view-2020/. Acesso em: 22 de julho de 2021.

BARBOSA, E. J. Q. Design de embalagens de alimentos orgânicos industrializados: análise da percepção dos aspectos ambientais e suas especificidades. Dissertação Design e Arquitetura (Mestrado). Faculdade de Arquitetura e Urbanismo, Universidade de São Paulo, São Paulo. 2014.

BÖLL H. F. Atlas do Plástico - Fatos e números sobre o mundo dos polímeros sintéticos. Rio de Janeiro, 2020.

Boomerang Alliance. Packaging is Wasting Australia. Boomerang Alliance, Sydney.2005

SÃO PAULO. PL 99/2019. Dispõe sobre a proibição de fornecimento de produtos plásticos de uso único nos locais que especifica. São Paulo: Câmara Municipal, [2019].

BRASIL. Resolução RDC no 259/2002. Aprova o Regulamento Técnico sobre Rotulagem de Alimentos Embalados. Diário Oficial da União. Brasília, DF: Poder Executivo. 2002.

COLTRO, L. et al. Reciclagem de embalagens plásticas flexíveis: contribuição da identificação correta. Polímeros, 23(1), 128-134. 2013.

COLTRO, L., et al. Reciclagem de materiais plásticos: a importância da identificação correta. Polímeros, 18(2), 119-225. 2009.

DAINELLI, D., et al. Active and Intelligent food packaging: legal aspects and safety concerns. Trends in Food Science and Technology, 19(1), 103-112. 2008.

DATAMARK. Dados Gerais. Disponível em: http://ppv.datamark.com.br/dadosgerais/. 2019. Acesso em: 22 de agosto de 2020

UE - União Europeia. Diretiva 2019/904. $(2019,6$, 5). Redução do impacto de determinados produtos plásticos no ambiente. União Europeia, Luxemburgo. 2019. 
FTI. ANNUAL AND SUSTAINABILITY REPORT.2019. Disponível em: https://www.ftiab.se/2557.html. Acesso em 02 de setembro de 2020.

IDEC. Pesquisa - embalagens de alimentos. Fev, 2005. Disponível em: http://www.idec.org.br/uploads/revistas_m aterias/pdfs/2005-02-ed85-pesquisaembalagens.pdf.fev,2005. Acesso em 03 de setembro de 2020 .

IPOS. A convergência entre saúde e meio ambiente no Brasil. Disponível em: https://www.tetrapak.com/pt-

br/sustainability/sustainability-updates.

Acesso em 20 de novembro de 2020.

ISO. GB/T 16288. Marcação de produtos plásticos. China. Abril, 2008.

KLAIMAN, K., et al. Barreiras percebidas para a reciclagem de embalagens de alimentos: evidências de uma experiência escolhida por consumidores dos EUA. Food Control, 73(B), 291-299. 2017.

LADIM, A. P. M. et al. Sustentabilidade quanto às embalagens de alimentos no Brasil. Polímeros, 26 (1). 2016.

LANGLEY, J., et al. Atributos da embalagem e influências sobre os resíduos. Packaging Technology Science, 24(3), 161-175. 2011.

MARKOWICZ, $\quad F ., \quad$ SZYMAŃSKAPULIKOWSKA, A. Analysis of the Possibility of Environmental Pollution by Composted Biodegradable and OxoBiodegradable Plastics. Geosciences. 9 (11). 460. 2019.

MEC. Consumo Sustentável - Manual de Educação. Disponível em: http://portal.mec.gov.br/dmdocuments/publ icaca08.pdf. 2005

NAPPER, I. E., THOMPSON, R. C. Environmental Deterioration of Biodegradable, Oxo-biodegradable, Compostable, and Conventional Plastic
Carrier Bags in the Sea, Soil, and Open-Air Over a 3- Year Period. Environmental Science \& Technology. 53 (9), 47754783. 2019.

NEGRÃO, C., CAMARGO, E. Design de embalagem: do marketing à produção. São Paulo: Novatec Editora. 2008

NETMAT, B. et al. The Role of Food Packaging Design in Consumer Recycling Behavior - A Literature Review. Sustainability, 11(16), 43-50. 2019.

NYSB. S01508C. Proibição de Sacolas e embalagens plásticas. Nova lorque. Abril, 2019

SDW. Swedish Waste Management. AvfallSverige, 2018.

SOE. Save on Energy - Recycling Symbols. 2020. Disponível em: https://www.saveonenergy.com/uk/recyclin g-symbols/. Acesso em: 20 de agosto de 2020.

Song, $\mathrm{H}_{\text {., }}$ et al. Biodegradable and compostable alternatives to conventional plastics. Philos Trans. R. Soc. Lond. B. Biol Sci. 364(1526), 2127-2139. 2009.

SWD. COM2018.028. A European Strategy for Plastics in a Circular Economy. Strasburg. Jan, 2018.

WORLD ECONOMIC FORUM. The New Plastics Economy - Rethinking the future of plastics. Geneva: World Economic Forum. 2016

WWF. Solucionar a poluição plástica: transparência e responsabilização. Mar,2019. Disponível em: https://www.wwf.org.br/?70222/Brasil-e-o4-pais-do-mundo-que-mais-gera-lixoplastico.. Acesso em: 25 de agosto de 2020.

YAM, K. L, et al. Intelligent packaging: Concepts and applications. Journal of Food Science, 70(1), 1-10. 2006. 